http://ejournal.ihdn.ac.id

\title{
AJARAN KELEPASAN DALAM LONTAR TUTUR KUMARA TATTWA
}

\author{
Putu Dana Yasa \\ Institut Hindu Dharma Negeri Denpasar \\ email: putu.dyasa@gmail.com
}

\begin{abstract}
ABSTRAK
Lontar Tutur Kumara Tatwa adalah salah satu lontar yang diwarisi oleh orang Bali saat ini. Tutur Kumara Tatwa memiliki ajaran yang bernilai tinggi, di Lontar Tutur Kumara Tatwa menjelaskan mengapa orang mengalami penderitaan dan bagaimana melepaskan penderitaan atau keterikatan untuk benar-benar mendapatkan kebebasan abadi atau moksa. Beberapa perpustakaan suci yang diwarisi termasuk Lontar Tutur Kumara Tatwa memiliki peran yang sangat penting dalam kehidupan manusia terutama umat Hindu di Indonesia. Lontar Tutur Kumara Tatwa berisi ajaran filosofis mengapa manusia yang terlahir sebagai makhluk paling mulia benar-benar mengalami penderitaan yang luar biasa dan bagaimana melepaskan semua keterikatan. Dalam Tutur Kumara Tatwa (2003: 65) dijelaskan bahwa Bhatara Kumara bertindak sebagai gembala, ia hidup sendirian di sebuah rumah gembala bernama Argakuruksana, karena sudah lama berada di tempat gembala, ia merasa bosan. Dia berpikir bahwa apa yang dia lakukan dan alami hanyalah kemiskinan dalam kehidupan. Sebenarnya ia bukan gembala sapi, tetapi menggembalakan dasendriya (sepuluh nafsu). dalam Lontar Tutur Kumara Tatwa disebutkan ada delapan cara untuk bisa lepas dari kebapaan agar mencapai pembebasan, setiap manusia selalu merasa tertekan, karena di dalam dirinya masih ada keraguan, kebingungan yang membuat orang takut untuk mengambil tindakan. Untuk mengantisipasi pengaruh sifat astadewi, Lontar Tutur Kumara Tatwa menjelaskan bahwa ada delapan cara pembersihan batin untuk menghindari pengaruh kekotoran batin yang disebut asta lingga.
\end{abstract}

Kata kunci: Pembebasan, Tutur Kumara Tattwa, Ajaran 


\section{PENDAHULUAN}

Manusia merupakan makhluk yang paling mulia apabila dibandingkan dengan makhluk lain yang ada di dunia ini. Dalam ajaran upanisad disebutkan bahwa manusia adalah manu atau kebijaksanaan, jadi manusia memiliki arti makhluk yang memiliki kebijaksanaan. Kebijaksanaan yang dimiliki oleh manusia dapat dilihat dari tiga kemampuan kodrati yang dimilikinya yaitu kemampuan berbicara atau sabda, kemampuan bergerak atau bayu, dan kemampuan berpikir atau idep. Makhluk selaian manusia hanya memiliki dua kemampuan yaitu kemampuan bergerak dan kemampuan bersuara. Bahkan pada tumbuhan hanya memiliki satu kemampuan yaitu kemampuan untuk tumbuh atau bergerak (bayu).

Kemampuan berpikir yang dimiliki oleh manusia akan menjadi lebih bijaksana apabila ditambahkan dengan pengetahuan-pengetahuan khusunya pengetahuan tentang agama. Pengetahuan tentang agama akan memberikan tuntunan bagi setiap manusia untuk mendapatkan jalan kebenaran dan tentunya dapat mencapai tujuan yang sesungguhnya dalam kehidupan ini. Manusia apabila tidak memiliki pengetahuan tidaklah berbeda dengan makhluk-makhluk yang lain, pengetahuan inilah yang menyebabkan manusia dianggap lebih mulia dibandingkan makhluk lain yang terdapat pada alam semesta ini.

Terlahir sebagai manusia bukanlah hal yang mudah, dikarenakan akan banyak hal yang perlu dilakukan guna memperbaiki karma demi mencapai suatu kebebasan abadi. Setiap makhluk yang terlahir sudah memiliki karmanya masingmasing, begitu pula manusia. Manusia terlahir kedunia tidaklah lain untuk memperbaiki segala macam perbuatan yang telah ia lakukan pada kehidupan sebelumnya. Dalam ajaran agama Hindu terdapat lima keyakinan yang disebut dengan panca sradha yang menjadi dasar umat Hindu dalam meyakini Tuhan. Bagian ketiga dari ajaran panca sradha adalah percaya dengan adanya karmaphala atau hukum sebab akibat.

Sejak Veda diwahyukan tujuan dari agama Hindu adalah "Moksartham Jagadhitaya Ca Iti
Dharma" yang memiliki arti bahwa Dharma bertujuan untuk mencapai kebahagian rohani dan kesejahteraan hidup jasmani atau secara sederhana diartika sebagai kebahagiaan lahir dan batin. Secara rinci tujuan agama Hindu disebutkan dalam Catur Purusa Artha yang artinya empat tujuan manusia yang terdiri dari dharma, artha, kama, dan moksa.Dharma artinya kebenaran atau kebajikan, yang berfungsi untuk menuntun umat manusia untuk mencapai kebahagian, artha artinya segala jenis benda atau materi yang dapat memenuhi segala kebutuhan hidup manusia, kamaartinya keinginan atau hawa nafsu, sedangkan moksa adalah kebahagiaan tertinggi atau kelepasan.

Secara umum tujuan umat Hindu adalah untuk mencapai kelepasan atau moksa. Moksa merupakan tujuan akhir dari setiap makhluk yang ada di alam semesta ini. Untuk mencapai moksa setiap manusia harus benar-benar tidak terikat oleh segala macam jenis keterikatan duniawi. Moksa berarti tiada keterikatan atma dengan bersatunya Brahman (Tuhan Yang Maha Esa). Di dalam Veda dijelaskan bahwa orang yang mencapai moksa, jauh dari kegelapan, memperoleh kebahagian tertinggi, keabadian dan terbebas dari ikatan kelahiran berulang-ulang, seperti dinyatakan dalam Yajurveda XXXI.18.

Dalam berbagai jenis pustak suci Hindu dijelaskan bagaiman cara untuk mencapaii sebuah kelepasan atau moksa. Salah satu pustaka suci yang membahas mengapa manusia menderita dan bagaiman cara untuk melepaskan diri dari penderitaan yaitu Lontar Tutur Kumara Tatwa. Lontar Tutur Kumara Tatwa merupakan salah satu naskah yang diwarisi oleh masyarakat Bali. Berpedoman dari uraian diatas, maka peneliti ingin mengkaji mengenai Ajaran Kelepasan dalam Lontar Tutur Kumara Tatwa.

\section{Pembahasan}

\subsection{Gambaran Umum Lontar Tutur Kumara Tatwa}

Lontar Tutur Kumara Tatwa merupakan salah satu lontar yang diwarisi oleh masyarakat Bali saat ini. Tutur Kumara Tatwa meniliki ajaran 
yang bernilai luhur, dalam Lontar Tutur Kumara Tatwa menjelaskan mengapa orang mengalami penderitaan dan bagaimana cara untuk melepaskan penderitaam atau keterikatan untuk benar-benar mendapatkan kebebasan abadi atau moksa. Beberapa pustaka suci yang diwarisi termasuk Lontar Tutur Kumara Tatwa memiliki peranan yang sangat penting dalam kehidupan manusia khusunya umat Hindu yang berada di Indonesia.

Lontar Tutur Kumara Tatwa memuat ajaran filosofis mengapa manusia yang terlahir sebagai makhluk paling mulia justru mengalami penderitaan yang sangat luar biasa dan bagaima pula cara untuk melepaskan semua keterikatan tersebut. Dalam Tutur Kumara Tatwa (2003:65) dijelaskan bahwa Bhatara Kumara berperan sebagai pengembala, ia tinggal sendiri didalam sebuah lading Pengembala bernama Argakuruksana. Karena sudah lama berada ditempat pengembala itu ia merasa bosan. Ia berpikir bahwa apa yang dilakukan dan dialaminya tidaklah lain merupakan kepapaan hidup. Sesungguhnya ia bukanlah mengembalakan sapi, melainkan mengembalakan dasendriya (sepuluh nafsu) yang termanifestasi dalam bentuk batin, cita-cita berlebihan menyebabkan kerja, budi berlebihan menimbulkan sikap suka mencela, hasrat berlebihan menimbulkan kerasukan, suara berlebihan menimbulkan keangkaraan, kekuatan berlebihan menimbulkan suka menipu, pikiran berlebihan menimbulkan kebingungan, omongan berlebihan menimbulkan suka mencerca, lupa berlebihan mengakibatkan tidaj tahu sumbernya, perjalanan yang berlebihan berakibat tujuan yang tidak jelas. Menurut Bhatara Kumara semua itu merupakan sumber penderitaan yang muncul akibat sepuluh indria yang disebut dengan dasendria.

Keinginan yang berlebihan atau kama (nafsu) merupakan salah satu musuh yang juga termasuk kedalam sad ripu dalam ajaran agama Hindu. Sad ripu merupakan enam musuh yang ada pada setiap manusia, yang terdiri dari nafsu atau kama, rakus dan serakah (lobha), cepat marah (krodha), mabuk (mada), moha (kebingungan), matsarya (iri hati). Enam musuh yang ada pada diri manusia ini mengakibatkan setiap manusia merasakan sangat jauh dengan kebahagiaan hidupnya. Bahkan apabila ke-enam musuh ini tidak dapat diseimbangkan maka keenam musuh ini akan menjadi sumber atau awal dari semua kesengsaraan yang kita alama dalam kehidupan ini.

Menurut Lontar Tutur Kumara Tatwa sepuluh nafsu atau dasendria yang terdapat di dalam manusia menyebabkan sepuluh kekotoran yang disebut dasamala. Dasamala tergolong dalam kelompok asubha karma, disamping terdapat tri mala, sad ripu, sad atatayi, dan sapta timira (Sura, 2001:17). Dasamala merupakan sumber dari kedursilaan, yaitu bentuk segala perbutan yang bertentangan dengan dharma.

Dasamala merupakan raja nafsu yang tidak lain adalah dasamukha (Rahwana). Nafsu akan terus mengalir dan menguasai hidup manusia. Dalam Bhagavadgita III.41 dijelaskan bahwa kama (nafsu) pastilah ada pada setiap orang. Kama inilah yang menggerakan orang untuk melakukan atau berbuat sesuatu, yang tentunya untuk memenuhi kebutuhan hidup sehari-hari. Kama merupakan suatu kekuatan atau energi yang membuat orang hidup dinamis, hidup lebih bergairah dan bersemangat. Kama merupakan hal yang alamiah, manusia sejak lahir sudah tidak bisa terpisah dengan kama, kama merupakan bagian integral dari sosok manusia.

Kama yang dikuasai oleh dharma akan tergolong dalam suatu hal yang bersifat baik, begitupun sebaliknya apabila kama hanya dikendalikan oleh sifat adharma maka sekecil apapun kama tersebut maka akan tergolong kedalam hal yang tidak baik pula. Untuk mengendalikan kama dibutuhkan kekuatan sradha dan pengendalian diri yang baik.

\subsection{Ajaran Kelepasan dalam Lontar Tutur Kumara Tatwa}

Bagian kelima sekaligus terakhir dalam ajaran panca sradha adalah percaya dengan adanya moksa. Moksa merupakan tujuan terakhir dalam keyakinan agama Hindu. Mencapai moksa artinya benar-benar sudah mencapai kebahagain yang sempurna. Moksa berarti tiada keterikatan atma dan bersatunya dengan Brahman (Tuhan Yang 
Maha Esa). Dalam Brahmanda Purana (3.4.3.5860) disebutkan tiga tingkatan moksa oleh orang yang melihat kebenaran, (1) kelepasan dari keterikatan ajnana (kebodohan), (2) keselamatan lepas dari ragasamksaya (hancurnya keterikata yang sangat mendalam/kemelekatan), (3) trsnaksaya (menghancurkan kehausan, seperti sangat terikat dengan keduniawian/kemelekatan indrawi).

Dalam beberapa pustaka suci agama Hindu disebutkan ada beberapa tingkatan moksa yang diajarkan dalam agama Hindu. Ajaran ini didasarkan pada keadaan atma dalam hubungannya dengan Brahman. Adapun tingkatan moksa yang dimaksud adalah sebagai berikut:

1. Jiwamukti adalah tingkatan moksa atau kebahagian/kebebasan yang dapat dicapai oleh seseorang semasa hidupnya, dimana atmanya tidak lagi terpengaruh oleh gejolak indrya dan unsur maya. Istilah ini dapat disamakan maksudnya dengan sampiya dan sarupya.

2. Widehamukti adalah tingkat kebebasan yang dapat dicapai oleh seseorang semasa hidupnya, dimana atmanya telah meninggalkan jasadnya, akan tetapi roh yang bersangkutan masih mendapat pengaruh maya.

3. Purnamukti adalah tingkat kebebaan yang paling sempurna. Pada tingkat purnamukti atma seseorang telah benar-benar menyatu dengan Brahman. Setiap orang akan mampu mencapai pada tingkat ini apabila yang bersangkutan sungguh-sungguh dengan kesadaran hati yang suci dan mampu melepaskan diri dari keterikatan atau keinginan keduniawian.

Dalam pustaka-pustaka suci Hindu sangat banyak yang membahas tentang kelepasan atau moksa, salah satunya yaitu Lontar Tutur Kumara Tatwa. Menurut lontar Kumara Tatwa, dasendrya didalam diri manusia menyebabkan sepuluh macam kekotoran yang menyebabkan manusia mengalami penderitaan ketika terlahir sebagai manusia. Sepuluh kekotoran itu disebut dengan dasamala yang terdiri dari :
1. Tandri artinya orang malas, suka maka dan tidur, tidak tulus, dan hanya melakukan kejahatan (Sura,2001). Sikap malas sebagai perbuatan yang patutnya sangat dihindari karena perbuatan ini hanya akan menghambat untuk mencapai kebahagian atau kelepasan yang tertinggi.

2. Kleda artinya berputus asa, suka menunda dan tidak mau menerima saran dari orang lain(Zoetmulder, 2004:509). Cepat berptus asa dan selalu menunda pekerjaan adalah sifat yang didominasi oleh sifat tamas. Manusia yang terpengaruh oleh sifat-sifat tamas maka atma yang ada pada dirinya akan jatuh ke neraka.

3. Leja artinya berpikir gelap, bernafsu besar dan gembira melakukan kejahatan (Zoetmulder, 2004:582). Pikiran merupakan hal yang paling penting yang menentukan kualitas perbuatan manusia .pikiran merupakan raja indrya, pikiran akan menjadi sahabat yang sangat luar biasa apabila mampu dikendalikan, dan juga sebaliknya pikiran akan menjadi musuh yang sangat luar biasa apabila kita tidak mampu menyeimbangkan dengan halhal yang bersifat positif.

4. Kutila artinya menyakiti orang lain , pemabuk, tidak jujur dan penipu, menyakiti dan membunuh makhluk lain, merupakan perbuatan yang bertentangan dengan ajaran agama (Zoetmulder, 2004:548). Kutila juga memiliki arti pemabuk. Ketika seseorang suka mabuk maka secara otomatis segala pikirannya akan menjadi gelap. Ketika pikiran sudah gelap maka orang tersebut akan melakukan hal-hal yang bersifat negatif misalnya menyakiti orang lain, berbohong dan sebagainya. Dalam lingkungan orang yang sering melakukan hal-hal tersebut maka akan mendapatkan nilai yang negatif di lingkungan masyarakatnya.

5. Kuhaka artinya pemarah, senang mencari kesalahan orang lain, berbohong, berkata sembarangan dan keras kepala 
(Zoetmulder, 2004: 528). Tidak mampu mengendalikan amarah akan berdampak negatif, karena dapat menimbulkan permasalahan yang besar khusunya dilingkungan masyarakat. Mencari-cari kesalahan orang lain adalah suatu hal yang patutnya tidak kita lakukan, alangkah bagusnya apabila setiap kesalahan yang dilakukan oleh orang lain kita gunakan sebagai media untuk intropeksi diri guna meningkatkan kualitas hidup kita sebagai manusia yang tidak pernah luput dari kesalahan. Kemarahan akan sangat merugikan kehidupan kita, oleh karena sepatutnya kita mampu mengendalikan emosi kita dalam keadaan apapun guna mendapatkan kebahagiaan dan kedamain. Ketika kita tidak mampu mengendalikan amarah terkadang kita akan kehilangan akal sehat sehingga dapat melakukan perbuatanperbuatan yang tidak patut kita lakukan.

6. Metraya adalah suku berkata menyakiti hati, sombong, irihati, dan suka menggoda istri orang lain ( Gede Sura, 2001). Dalam sarasamuccaya 120 dijelaskan bahwa perkataan yang mengandung maksud jahat tiada bedanya dengan anak panah yang dilepas, setiap ditempuhnya merasa sakit, perkataan itu meresap kedalam hati sehingga menyebabkan tidak bisa makan dan tidur baik siang maupaun malam hari, oleh karena itu tidak diucapkan perkataan itu oleh orang yang budiman dan wiraperkasa, pun oleh orang yang tetap suci hatinya (Kajeng, 2003:100). Berdasarkan uraian tersebut maka dapat disimpulkan bahwa setiap perkataan yang kita keluarkan merupakan hal yang sangat berbahaya apalagi perkataan yang dapat menyinggung perasan orang laian. Dalam Nitisastra, Sargah V. bait 3 juga disebutkan "wasista nimitanta manemu laksmi, wasita nimitanta pati kapangguh, wasita nimitanta manemu dukha, wasita nimitanta manemu mitra" yang artinya karena berbicara engkau menemukan kebahagiaan, karena berbicara engkau mendapatkan kematian, karena berbicara engkau menemukan kesusahan, dan karena berbicara pula engkau mendapatkan sahabat. Jadi sebelum seseorang berbicara hendaklah dipikirkan terlebih dahulu agar tidak ada yang merasa terganggu dengan apa yang ingin disampaikan.

7. Megata artinya berbuat jahat, berkata manis tetapi pamrih (Zoetmulder, 2004:663). Dalam kehidupan sehari-hari terkadang kita menemukan seseorang yang berbicara lain dimulut lain pula dihati, berkata manis karena ada yang diinginkan, hal tersebut merupakan perbuatan yang dilakukan oleh orang yang terlalu pamrih, secara tidak sadar hal ini dapat menghambat kita untuk mendapatkan kelepasa yang sesungguhnya.

8. Ragastri artinya bernafsu dan suka memperkosa (Zoetmulder, 2004:900). Sifat ragastri sangatlah jelas merupakan perbuatan yang sangat bertolak belakang dengan ajaran agama. Sifat seperti itu merupakan sifat keraksasaan. Perbuatan memperkosa merupakan perbuatan yang sangat terkutuk dalam ajaran agama. Agar dapat mengendalikan sifat ragastri hendaknya mampu mengendalikan pikiran dan hawa nafsu yang merupakan sesungguhnya memang tidak akan terlepas pada diri kita. Akan tetapi, hal tersebut dapat diseimbangkan dengan memahami secara jelas ajaran-ajaran agama yang tentunya akan dapat memberikan jalan untuk menuju kebahagiaan.

9. Bhaksa Bhuana artinya suka menyakiti orang lain, penipu, dan berpoya-poya (Zoetmulder, 2004 : 135). Berpoya-poya artinya menggunakan artha melebihi batas normal. Penyalahgunaan artha juga dapat berakibat buruk pada diri seseorang. Contohnya, seperti mabuk-mabukan, mencari wanita penghibur dan sebagainya. Hal tersebut merupakan perbuatan yang bertolak belakang dengan ajaran dharma. Dalam lingkungan masyarakat akan kita 
jumpai apabila ada seseorang yang hanya berpoya-poya maka hidupnya akan menderita baik secara lahir maupun batin.

10. Kimburu artinya penipu dan pencuri terhadap siapa saja tidak pandang bulu, pendengki dan iri hati. Dalam ajaran agama Hindu mencuri, menipu, dan irihati merupakan perbuatan yang tergolong dalam asubha karma yang tentunya sangat wajib untuk kita hilangkan. Ciri utama orang yang irihati dan pendengki adala tidak akan pernah senang melihat orang lain bahagia. Untuk mendapatkan kebahagiaan hendaknya sifat tersebut harus dihilangkan agar benar-benar terbebas dari segala jenis keterikatan.

Demikianlah sepuluh kekotoran yang menyebabkan manusia dalam kehidupannya merasakan penderitaan dan susah untuk mencapai kelepasa, atau moksa. Lontar Tutur Kumara Tatwa menjelaskan bahwa meruat kepapaan yang diakibatkan oleh pengaruh Dasamala sangatlah susah. Selain dasamala juga terdapat delapan kekuatan dalam diri manusia yang dapat membuat hidup manusia menjadi papa yang disebut dengan astadewi atau pracanamaya. Adapun bagianbagian dari astadewi atau pracanamaya yaitu sebagai berikut:

1. Jayasidi merupakan kekuatan pikiran yang bersikukuh pada kemampuan diri berlebih, sangat senang dipuji dan tidak pernah mau menagalah.

2. Caturasani artinya senang mengumbar kehendak, dan senang mencela orang lain.

3. Namadewi artinya sifat egois, suka mengutuk dan berlagak kuasa.

4. Mahakroda artinya suka marah, berbohong, buta hati dan sangat kasar.

5. Camundi artinya suka berkata berbelit-belit, tidak tetap pendirian, tidak berbakti, dan selalu ingin menang sendiri

6. Durgadewi artinya berpikir sangat susah, tidak cermat, selalu berperilaku jahat

7. Sirni artinya suka bersenang-senang, suka mengaku-ngaku, dan batinnya hampa
8. Wighna artinya penuh nafsu, senang melebih-lebihkan perkataan, suka menghina kebaikan, bingung.

Delapan sifat tersebut membawa manusia selalau berada dalam kepapaan, selalu merasakan kesusahan, karena didalam dirinya masih terdapat keragu-raguan, kebingungan yang membuat manusia akan takut untuk melakukan tindakan. Untuk mengantisipasi pengaruh dari sifat astadewi, Lontar Tutur Kumara Tatwa menjelaskan terdapat delapan cara pembersihan batin agar terlepas dari pengaruh kekotoran yang disebut dengan astalingga.

Astalingga merupakan cara yang ditawarkan oleh Tutur Kumara Tatwa untuk mendapatkan pembersihan diri dan agar tidak terpengaruh oleh sifat astadewi yang tentunya akan menghambat manusia untuk menyau dengan Brahman. Astalingga terdiri dari:

1. Sudha adalah penyucian pikiran

2. Sphatika artinya menenangkan pikiran

3. Sunya artinya mengosongkan pikiran

4. Mahatana adalah memikirkan hal-hal yang luhur

5. Prabhaswara artinya membawa pikiran memenuhi alam semesta

6. Nirawarana artinya membawa pikiran tiada terbatas

7. Nirmala adalah menghindarkan pikiran dari hal-hal yang kotor

8. Niskala artinya membuat pikiran tidak goyah

Dalam Lontar Tutur Kumara Tatwa dijelaskan bahwa Bhatara Kumara mampumeninggalkan astadewi sebagai sumber kekotoran ataupun penderitaan dengan menerapkan ajaran astalingga tersebut. Setalah Bhatara Kumara benar-benar mampu menguasai dan mengendaikan astadewi tersebut kemudia Bhatara Maheswara menganugrahkan delapan sifat kemuliaan kepada Bhatara Kumara. Delapan sifat kemuliaan tersebut yaitu:

1. Saraswati adalah kemampuan dan pengetahuan untuk memahami ajaran agama 
2. Laksmi adalah kemampuan untuk membedakan hal yang baik dan buruk

3. Upeksa adalah peka mengatasi kesulitan

4. Karuna adalah sayang kepada semua makhluk

5. Mudita adalah bersikap simpati dan adil

6. Santa adalah bertutur kata manis

7. Prajna adalah mengutamakan kebaikan

8. Parimita adalah sadar kepada diri sendiri sebagai sesuatau yang terbatas adanya.

Dengan mendapatkan delapan anugrah dari Bhatara Maheswara tentunya Bhatara Kumara mendapatkan kebahagian yang sesunggunya. Untuk mencari kebahagiaan yang sesungguhnya dalam ajaran agama Hindu sesungguhnya adalah penekanan untuk mengenali jauh kedalam diri kita sendiri, karena sesungguhnya didalam diri manusia ini terdapat suatu hal yang benar-benar harus kita dalami untuk mendapatkan kelepasan serta kebahagiaan yang sesungguhnya.Dalam kisah Lontar Tutur Kumara Tatwa setelah Bhatara Kumara mendapatkan kekuatan dari Bhatara Guru, Bhatara Kumar menghilang dan tidak satupun para dewa yang mengetahui keberadaannya.

Sebagaimana dikisahkan dalam Lontar Tutur Kumara Tatwa setelah Sang Hyang Kumara mendapatkan kekuatan dari Bhatara Guru, maka Sang Hyang Kumara menghilang dan tidak ada yang dapat mengetahui keberadaannya bahkan oleh para Dewa seklipun. Sementara itu Bhatara Jati Niyasa melakukan pemujaan kepada Bhatara Guru dan Bhatara Jati Niyasa juga mampu mengendalikan astadewi melalui astalingga dan menapatkan anugerah yang sama seperti yang didapatkan oleh Bhatara Kumara. Sehingga Bhatara Jati Niyasa bertemu dengan Bhatara Kumara, begitu pula Bhatara Guru manunggak bersamanya. Wujud menyatunya atma dengan Brahman sesunggunya adalah kembali pada kekosongan (sunyapada) dimana budi tak terikat waktu (buddhi niskala). Hal itulah yang dikatakan sebagai pembebasan sempurna dalam Lontar Tutur Kumara Tatwa.

Dalam Tutur Kumara Tatwa (2003:76), dijelaskan bahwa terdapat tiga perwujudan Tuhan, yaitu Siwa, Sadasiwa, dan Paramasiwa. Hakikat Siwa diumpamakan matahari membayangi air didalam temapayan. Sadasiwa bagaikan matahari bersinar. Sadasiwa bagaikan langit. Ketiganya akan saling bersambut. Siwa adalah jiwa dari tubuh, sumber tunggal yang berwujud banyak,Sadasiwa merupakan yang tunggal, tetapi menyerap dan menyusupi segalanya. Bagaikan api dalam bara yang memenuhi tungku. Paramasiwa merupakan hal yang tidak bisa dibayangkan, tidak berwujud.

Siwa adalah segala sesuatu yang memenuhi alam semesta, dia adalah jiwa Brahman. Sadasiwa menyerap dan meliputi seluruh kelahiran. Paramasiwa tak terbayangkan dan meresap dalam semua makhluk, berada dalam unsur tetapi bukam unsur itu sendiri, ada didalam kosong akan tetapi tidak kosong. Siwa merupakan sumber segala yang ada, Sadasiwa menguasai segalanya. Paramasiwa adalah hakikat yang tertinggi. Dia akan menjadi nyata dan terkira apabila perwujudannya yang rahasia dalam pikiran dibayangkan dalam batin dan dapat diperbanyak. Dia akan menjadi nirbana jika wujudnya hilang dalam keheningan batin, diri dan alam semesta.

\section{Simpulan}

Dalam Lontar Kumara Tatwa dijelaskan bahwa Bhatara Kumara berperan sebagai seorang pengembala. Ia tinggal sendiri disebuah lading pengembala bernama Argakuruksana. Karena sudah sangat lama berada ditempat pengembala itu, Bhatar Kumara merasa bosan. Bhatara Kumara menganggap apa yang dialami dan dilakukannya di lading pengembala itu tidaklah lain sebagai sebuah kepapaan hidup. Ia bukanlah mengembalakan sapi tetapi mengembalakan Dasendria, yang termanifestasi dalam bentuk batin, cita-cita berlebihan, budi berlebihan, hasrat berlebihan, suara berlebihan, pikiran berlebihan, omongan berlebihan, lupa berlebihan, perjalanan berlebihan. Menurut Bhatara Kumara semua itu merupakan sumber-sumber penderitaan yang muncul akibat Dasendria (sepuluh indria).

Menurut Lontar Tutur Kumara Tatwa sepuluh nafsu didalam diri manusia menyebabkan 
sepuluh kekotoran yangdisebut dasamala. Dasamala merupakan raja nafsu yang tiada lain adalah Dasamukha. Nafsu itu akan terus mengalir membelenggu kehidupan manusia.

Selain Dasamala juga terdapat delapan penyebab kepapaan yang disebut dengan astadewi yang merupakan penghambat manusia untuk mencapai kebebabasan atau kelepasan sempurna. Dalam Lontar Tutur Kumara Tatwa dijelaskan terdapat delapan cara untuk mengantisipasi astadewi yang disebut astalingga. Dalam Lontar Tutur Kumara Tatwa dijelaskan Bhatara Kumara mampu mencapai kelepasan sempurna dengan memahami dan mendalami ajaran astalingga. Setelah memahami ajaran astalingga, Bhatara Kumara mendapatkan anugrah dari Bhatara Guru yaitu berupa delapan sifat kemuliaan.

\section{DAFTAR PUSTAKA}

Dinas Kebudayaan Provinsi Bali. 2003. Kajian Naskah Lontar Tutur Kumara Tatwa. Denpasar.

Kamajaya, Gede. 2001. Alam Kehidupan Sesudah Mati. Surabaya: Paramita.

Titib, I Made. 2006. Persepsi Umat Hindu Di Bali Terhadap Svarga, Naraka, Dan Moksa Dalam Svargarohanaparva Perspektif Kajian Budaya. Surbaya: Paramita. 